\title{
Preliminary evaluation of hepatoprotective and nephroprotective effects of Prosopis ruscifolia Griseb. leaves extract in mice
}

\author{
María S. Soverina, Miguel A. Campuzano-Bublitz, Juan R. Centurión, Antonia K. Galeano, María L. Kennedy* \\ Departamento de Farmacología, Facultad de Ciencias Químicas, Universidad Nacional de Asunción, Campus UNA, San Lorenzo, Paraguay.
}

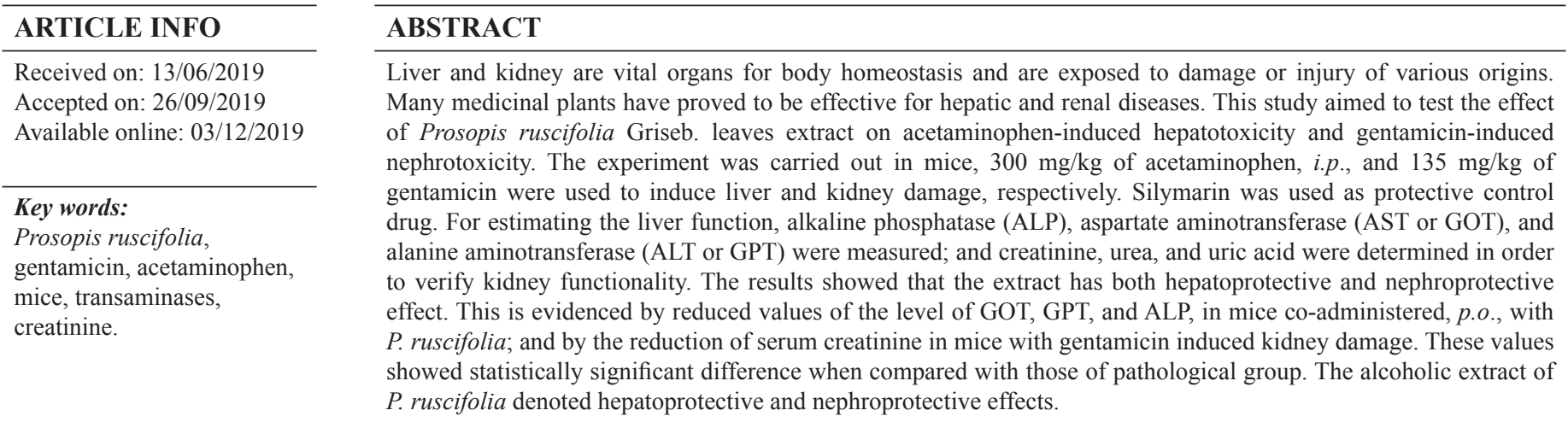

\section{INTRODUCTION}

Many drugs, chemical, or other agent can cause damage or injury to the liver, and hepatotoxicity is the most frequent cause for acute liver failure (Andrade et al., 2007). Liver is the key homeostasis regulating organ, and it is involved with several biochemical pathways that regulate many physiological activities such as growth, reproduction, defense, nutrient supply, and energy production. As much as $10 \%$ of hepatitis cases in adults overall is due to drug-induced liver injury (Reddy et al., 2013). The excretion of xenobiotic is mainly through the kidneys, they are exposed to free radicals which contribute to high oxidative stress that contributes to the kidney damage (Carpenter and Mudge, 1981).

Medicinal plants have been proved to be an effective treatment for several diseases, but until today, accurate safety and efficacy information is lacking. One classical medicine for liver disease is

\footnotetext{
"Corresponding Author

Maria L. Kennedy, Departamento de Farmacolgía, Facultad de Ciencias Químicas, Universidad Nacional de Asunción, Campus UNA, San Lorenzo, Paraguay. E-mail: lukenrol @qui.una.py
}

silymarin, which is claimed to be safety and effective (Bean, 2002; White et al., 2007). Glycyrrhizin, from licorice root, is able to reduce serum transaminases, due to inhibitory effects on cytokines in the liver (Coon and Ernst, 2004; Li et al., 2014); and ginger rhizome has been used to treat lamotrigine-induced hepatotoxicity in rats (Poorrostami et al., 2014).

The plant Prosopis ruscifolia belongs to the family Fabaceae, and it is used in folk medicine mainly for diabetes and hyperlipidemia (Polini and Romero, 2013). We have previously demonstrated that this plant possess antihyperglycemic (CampuzanoBublitz et al., 2016) and cardioprotective (Campuzano-Bublitz et al., 2019) effect. Considering that $P$. ruscifolia is used for a long-term treatment in case of diabetes, we proposed to investigate the effect of the alcoholic extract of the leaves on the liver and kidney after acute treatment, against acetaminophen-induced hepatotoxicity and gentamicin-induced nephrotoxicity in mice, in such a way to provide data on the long-term safety of the plant.

\section{MATERIALS AND METHODS}

\section{Plant material and extraction}

Prosopis ruscifolia Griseb. (Fabaceae) leaves were collected in Teniente Irala Fernández, Paraguay. A voucher specimen 
was filed with the herbarium of Facultad de CienciasQuímicas, Universidad Nacional de Asunción (Degen 4581). Dried and powdered samples were extracted with ethanol and concentrated to dryness under reduced pressure in a vacuum rotatory evaporator. The suspension of extract in distilled water was used in the experiment.

\section{Drugs}

Acetaminophen or Paracetamol (Sigma Chemical Company Mo.), Gentamicin (LASCA Pharmaceutical), silymarin (Sigma Chemical Company Mo.), and sodium pentobarbital (Nembutal) from Abbott (Japan) were used; ethanol was purchased locally and distilled before use. Kits for the estimation of alkaline phosphatase (ALP), aspartate aminotransferase (AST or GOT), alanine aminotransferase (ALT or GPT), creatinine, urea and uric acid were purchased from Human Diagnostics Worldwide reagent, the measurements were done in a Biosystem BTS 350 semi-automatic analyzer.

\section{Experimental animals}

Swiss albino male and female mice, weighing 25-35 g were used. The animals were housed in plastic cage at a constant room temperature $\left(23^{\circ} \mathrm{C}-25^{\circ} \mathrm{C}\right)$, with $12: 12$ hours light-dark cycle, in humidity controlled environment $(50 \%-60 \%)$. They were fed daily with standard animal pellets and water ad libitum. All assays were conducted in accordance with international standards of animal welfare and the research protocol was approved by the Bioethical Committee of the Facultad de Ciencias Químicas (CEI 387/18). The minimum number of animals and duration of observation required to obtain consistent data were used, each animal was used once (Guide for the Care and Use of Laboratory Animals, 2011).

\section{Acetaminophen induced hepatotoxicity and treatments}

Swiss albino male mice were randomly divided into six groups $(n=8)$, and orally treated for 4 days: Vehicle group (V; $2.5 \%$ ethanol: $40 \%$ propylene glycol: $57.5 \%$ water); Acetaminophengroup (APAP; water); Silymarin group (SM; 150 $\mathrm{mg} / \mathrm{kg}$ of silymarin, p.o.); Groups Pr50, Pr100, Pr200 (treated with 50, 100, and $200 \mathrm{mg} / \mathrm{kg}$ of Pruscifolia extract, respectively, p.o.). On the 4th day, acute hepatotoxicity was induced with acetaminophen (APAP), 2 hours after the oral treatment, all animals, except the ones in the vehicle group, received $300 \mathrm{mg} / \mathrm{kg}$, i.p., of APAP (Mossanen and Tacke, 2015). Three hours after APAP administration, blood sample was collected by cardiac puncture after anesthesia with sodium pentobarbital ( $50 \mathrm{mg} / \mathrm{kg}$, i.p.). Serum GOT, GPT, and ALP were determined.

\section{Gentamicin-induced nephrotoxicity and treatments}

Swiss albino female mice were randomly divided into seven groups $(n=8)$ and received orally for 9 days the treatment. Saline group (saline solution; $0.1 \mathrm{ml} / 10 \mathrm{~g}$ body weight); Vehicle group (Veh; $2.5 \%$ ethanol: $40 \%$ propylene glycol: $57.5 \%$ water); Gentamicin group (G; water $0.1 \mathrm{ml} / 10 \mathrm{~g}$ body weight and gentamicin); Silymarin group (SM; $150 \mathrm{mg} / \mathrm{kg}$ body weight, silymarin, p.o., and gentamicin); groups Pr50, Pr100, and Pr200 (treated with 50,100, and $200 \mathrm{mg} / \mathrm{kg}$ of $P$. ruscifolia extract, respectively, and gentamicin). Every day, all animals, except saline and vehicle groups, received gentamicin $(135 \mathrm{mg} / \mathrm{kg}$ body weight, i.p.) 1 hour after the oral administration of the different treatments. On day 10th, 24 hours after the last dose of gentamicin, animals were anesthetized with sodium pentobarbital $(50 \mathrm{mg} / \mathrm{kg}$, i.p.) and blood extraction by cardiac puncture was performed. Serum creatinine, urea, and uric acid were measured.

\section{Determination of biochemical parameters}

The biochemical parameters of GPT, GOT, ALP, creatinine, urea, and uric acid were determined from the serum. In order to obtain the blood serum, the fresh blood samples were incubated in a water bath for 20 minutes and then subjected to centrifugation for 15 minutes at 3,000 rpm. The samples were processed immediately after they were obtained. Control serum (normal and pathological Humatrol) was processed before each determination, as an internal quality control, and the values obtained for the different biochemical parameters were always within the expected ranges.

\section{Statistical analysis}

The data were processed using the GraphPad Prism 7.0. (GraphPad Software, Inc., CA). The analysis of variance (ANOVA) of one factor followed by Tukey test was used for the statistical analysis. The results were expressed as mean \pm standard deviation (SD) and a value of $p<0.05$ was considered statistically significant.

\section{RESULTS AND DISCUSSION}

The extract of $P$. ruscifolia (Pr) has previously showed activity in hyperglycemic rats and mice, reducing blood glucose level and showing cardioprotective effect (CampuzanoBublitz et al., 2016; 2019). As part of our project concerning the investigation on medicinal properties of this plant, we have studied the activity of Pr leaves extract on acetaminophen-induced hepatotoxicity and gentamicin-induced nephrotoxicity. This paper reports on the protective effect on both liver and kidney of mice.

\section{Effect of $\boldsymbol{P}$. ruscifolia leaves extract on liver profile parameters}

The oral administration of $P$. ruscifolia showed significant effect reducing serum GOT, GPT, and ALP levels elevated by acetaminophen. All animals treated with the extract, that is, 50,100 , and $200 \mathrm{mg} / \mathrm{kg}$, exhibited significantly reduced levels of enzymes GOT ( $p<0.0001)$, GPT $(p<0.0001)$, and ALP $(p<0.001$ in $\operatorname{Pr} 50 ; p<0.0001$ in $\operatorname{Pr} 100$ and $\operatorname{Pr} 200)$ when compared to the APAP group (pathological control). Even though all the Prtreated groups had no significant difference between them in any of the measured parameters, according to the Figure 1, it could be possible to distinguish a slightly dose dependent effect (Fig. 1). Moreover, it should be noted that the SM group exhibited no difference from vehicle-treated mice (Veh) in any of the measured biochemical parameters. Taking into account that silymarin was dissolved in a mixture of ethanol:propyleneglycol:water, the vehicle group received this mixture to verify that it had no effect on the measured enzymes and that the observed reduction in enzymes activities was really due to the drug silymarin. With these results, it is possible to affirm that the model of acute liver injury caused by acetaminophen was validated.

The activities of serum enzymes GPT and GOT are sensitive indicators of liver cell injury and along with ALP enzyme 
are helpful in recognizing hepatic diseases. In this work, the results indicated (Fig. 1) that administration of acetaminophen to the group that had received only distillated water significantly increased serum levels of biochemical parameters including GPT, GOT, and ALP activities (group APAP) in comparison with the group that received the vehicle $(p<0.0001)$. This confirms the hepatotoxic effect of $300 \mathrm{mg} / \mathrm{kg}$ of APAP in the mice model used. In silymarintreated mice (group SM), all these parameters, unlike ALP, were significantly attenuated $(p<0.0001)$ when compared to the pathological group (APAP). This fact is consistent with literature data which affirm that the protective effect of silymarin is found in the eradication of pathological events such as inflammation, necrosis, and elevated transaminase levels (Papackova et al., 2018). This corresponds mainly to hepatocellular involvement of the liver.

\section{Effect of $p$. ruscifolia extract on the parameters of the renal profile}

Results presented in this study confirmed that gentamicin administration caused marked changes in kidney tubules due to gentamicin reabsorption in proximal convoluted tubules, causing degeneration and necrosis of the epithelial cells of the tubules. These changes are manifested by dilated tubules, loss of brush border, severe leucocyte infiltrations, tubular degeneration, and presence of tubular casts (Randjelović et al., 2017). These findings are in agreement with previous studies. The intraperitoneal administration of $135 \mathrm{mg} / \mathrm{kg}$ of gentamicin for 9 consecutive days to healthy mice caused serum creatinine levels significantly higher $(p<0.0001)$ than those of group Sal and Veh (Fig 2A). Creatinine level is a serum marker frequently used in the diagnosis and prognosis of nephropathies, is a waste product excreted mainly by filtration, the increase in serum indicates decreased excretion due to failing in renal function (Ishihara and Hirano, 2002). Together with urea levels, they allow to evaluate the renal functionality. These parameters and also uric acid tend to be altered in the case of kidney damage (Manikanadan et al., 2011). In silymarin-treated mice, this parameter was significantly attenuated $(p<0.01)$ when compared to the pathological group (group Gent). In addition, the statistical analysis revealed that there were no significant differences in the level of serum creatinine between the group treated with silymarin and the Sal and Veh groups. The level of serum specific renal function parameter creatinine was significantly increased in gentamicin administered mice, and oral co-administration of $P$. ruscifolia leaves extract $(50,100$, and $200 \mathrm{mg}$ ) was able to significantly decrease serum creatinine levels, compared to the pathological group $(p<0.001$ for groups $\operatorname{Pr} 50$ and $\operatorname{Pr} 100 ; p<0.05$ for group $\operatorname{Pr} 200)$. Related to the level of urea and uric acid, the same tendency as creatinine was observed with the different groups of animals, as depicted in the Figure 2 (Fig. 2b and c). However, despite the visual trends, the statistical analysis did not reveal significant differences between the groups.

Unlike that the information reported in other similar studies with the same model of acute renal injury in mice (Aldahmash et al., 2016), in this work, a higher gentamicin dose was used. However, not all parameters of the renal profile evaluated from the pathological group showed a significant
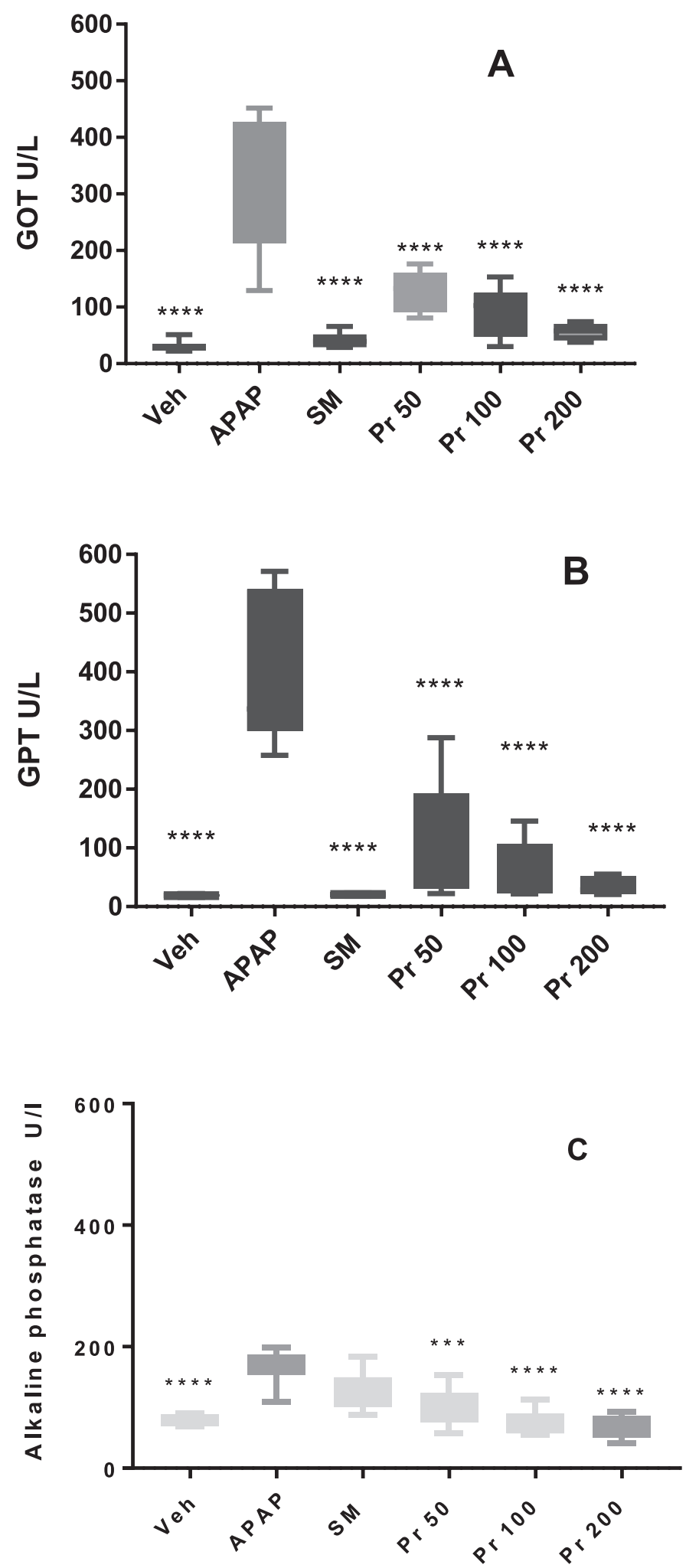

Figure 1. Serum levels (U/1) of GOT (A), GPT (B), and Alkaline phosphatase (C) of mice $(n=8)$ treated with Prosopis ruscifolia leaves extract. The data are plotted as average \pm SD. ANOVA of one factor, followed by the Tukey test was used, $p<0.05$ was considered statistically significant $(* * * p<0.001$, $* * * * p<0.0001$; significantly different from APAP). 

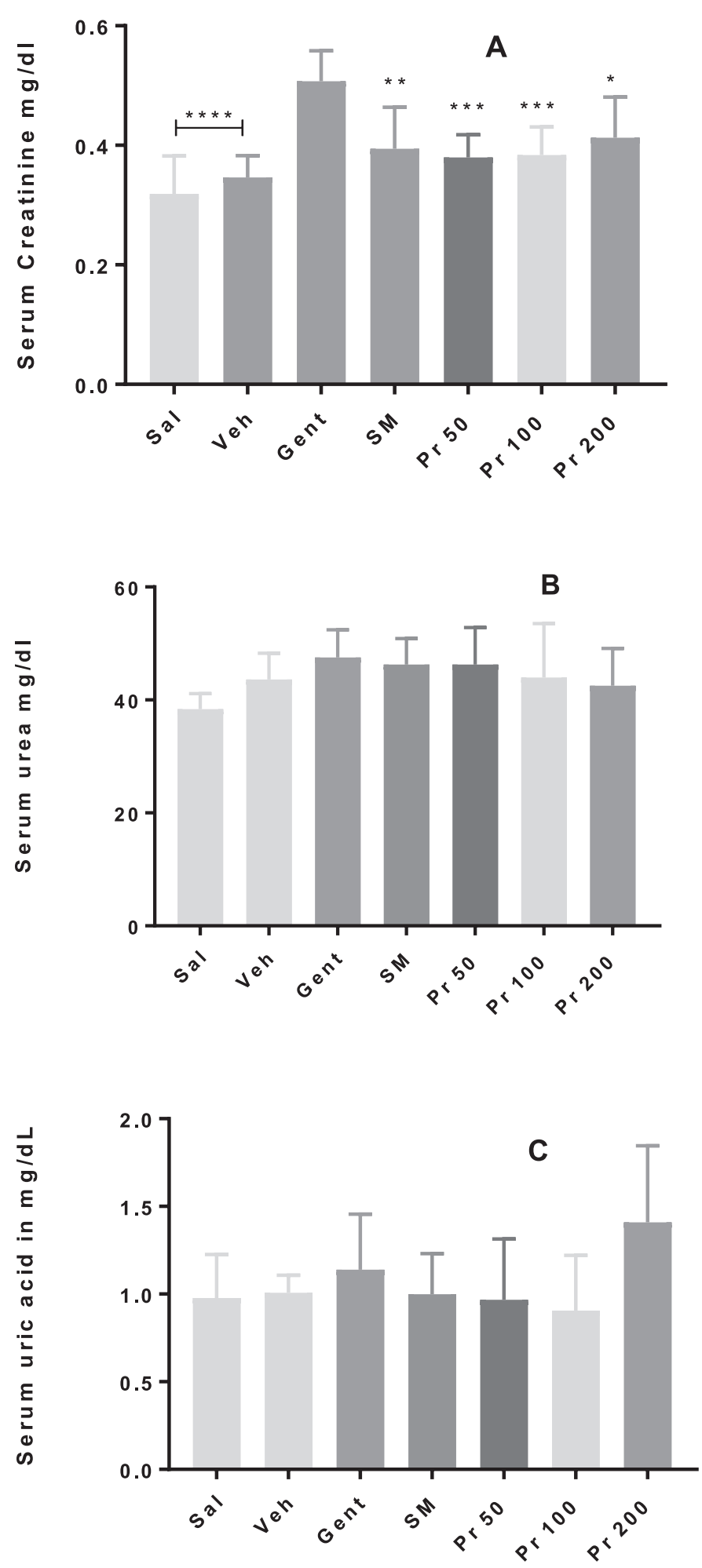

Figure 2. Serum levels $(\mathrm{mg} / \mathrm{dl})$ of creatinine(A), urea (B), and uric acid (C) of mice $(n=8)$ treated with Prosopis ruscifolia leaves extract. The data are plotted as average \pm SD. ANOVA of one factor followed by the Tukey test was used, $p<0.05$ was considered statistically significant $\left(* p<0.05,{ }^{*} * p<0.01\right.$, $* * * p<0.001, * * * * p<0.0001$; significantly different from Veh). elevation with respect to the groups Sal and Veh as expected. The dose and duration of the treatment with gentamicin determine the renal damage, reported doses used in literature to produce renal damage range between 8 and $80 \mathrm{mg} / \mathrm{kg} /$ day (Lee and Michael, 1985). Toxic effects appear if five to ten times of normal doses are administered (Tulkens, 1989). In this study, a daily dose of 135 $\mathrm{mg} / \mathrm{kg}$ of gentamicin for 9 days was used; some authors reported rise in serum creatinine (Tulkens, 1989) with 30-60 mg/kg/day of gentamicin for 5 to 10 days, in agreement with our findings for gentamicin treated animals. Aminoglycosides have nephrotoxic effect due to induction of Reactive oxygen species (ROS) and depletion of antioxidant enzyme activities in the kidney (Tavafi and Ahmadvand, 2011).

The protective effect of $P$. ruscifolia may be due to phenolic compounds present in this extract, as previously demonstrated with the presence of quercetin, that could mediate the protective effect through their ability of scavenging free radicals and active oxygen species such as single oxygen, free radicals, and hydroxyl radicals (Campuzano-Bublitz et al., 2019). Additionally, it has been suggested that polyphenolic and flavonoids in the diet are associated with longer life expectancy. Moreover, nephron protective effect of vitamin E mediated by its antioxidant effect has been proved (Salih, 2015). This plant contains quercetin. Flavonoids are considered one of the major groups of antioxidants acting efficiently as scavengers of free radicals (Da Silva et al., 2011). It was clear that this extract alleviated the toxic potentials of acetaminophen and gentamicin, on the liver and kidney, respectively. Finally, liver protection capability of Prosopis farcta was demonstrated, and attributed to its high contents of various flavonoids that act as powerful antioxidants and free radical scavengers (Alharbi et al., 2017; Asadollahi et al., 2014) and the stem bark of $P$. cineraria also proved hepatoprotective activity, against $\mathrm{CCl} 4$ induced hepatotoxicity due to the content of flavonoids an tannins (Velmurugan and Ganesan, 2014). To establish the exact mechanism of protection of the liver and kidney will require further research.

\section{CONCLUSION}

It can be concluded from the results obtained that the ethanolic extract of the leaves of P. ruscifolia has hepatoprotective and nephroprotective effect. All doses tested were able to decrease the level of hepatic GOT, GPT, and ALP induced by acetaminophen, andrenal creatinine induced by gentamicin.

\section{AUTHORS' CONTRIBUTIONS}

María S. Soverina, Miguel A. Campuzano-Bublitz, Juan R. Centurión, and Antonia K. Galeanoand María L. Kennedy carried-out the laboratory work and the data analysis. María S. Soverina, Miguel A. Campuzano-Bublitz, and MaríaL. Kennedy designed the experiments and drafted the manuscript. All the authors have read the final manuscript and approved the submission.

\section{ACKNOWLEDGMENTS}

The authors would like to thank Professor Rosa Degen who identified the plant material. 


\section{CONFLICT OF INTEREST}

The authors declare that they have no conflicts of interest.

\section{FINANCIAL SUPPORT}

This research was fully supported by research grant from Consejo Nacional de Ciencia y Tecnología, CONACYT, Paraguay (Project PINV15-378) and Facultad de Ciencias Químicas, Universidad Nacional de Asunción, Paraguay.

\section{REFERENCES}

Aldahmash BA, El-Nagar DM, Ibrahim KE. Reno-protective effects of propolis on gentamicin-induced acute renal toxicity in swiss albino mice. Nefrologia, 2016; 36(6):643-52.

Alharbi KB, Mousa HM, Ibrahim ZH, El-Ashmawy IM. Hepatoprotective Effect of Methanolic Extracts of Prosopis farcta and Lycium shawii Against Carbon Tetrachloride-induced Hepatotoxicity in Rats. J Biol Sci, 2017; 17(1):35-41.

Andrade RJ, Robles M, Fernández-Castañer A, López-Ortega $\mathrm{S}$, López-Vega MC, M Isabel Lucena MI.Assessment of drug-induced hepatotoxicity in clinical practice: a challenge for gastroenterologists. World J Gastroenterol, 2007; 13(3):329-40.

Asadollahi A, Sarir H, Omidi A, Torbati MB. Hepatoprotective Potential of Prosopis farcta beans Extracts against acetaminophen-induced hepatotoxicity in wister rats. Int J Prev Med, 2014; 5(10):1281-5.

Bean P. The use of alternative medicine in the treatment of hepatitis C. Am Clin Lab, 2002; 21(4):19-21.

Campuzano-Bublitz MA, Diarte EMG, Hellion-Ibarrola MC Ibarrola DA, Alvarenga NL, Kennedy ML. Effect of Prosopis ruscifolia on lipid profile in alloxan-induced hyperglycaemic mice and chemical characterization of alkaloid and flavonoid fractions. J App Pharm Sci, 2019; 9(06):86-93.

Campuzano-Bublitz MA, Ibarrola DA, Hellion-Ibarrola MC, Dölz JH, Kennedy ML. Acute and chronic anti-hyperglycemic effect of Prosopis ruscifolia extract in normoglycemic and alloxan-induced hyperglycemic rats. J App Pharm Sci, 2016; 6(05):178-84.

Carpenter HM, Mudge GH. Acetaminophen nephrotoxicity: studies on renal acetylation and deacetylation. J Pharmacol Expl Therap, $1981 ; 218: 161-7$.

Coon JT; Ernst E. Complementary and alternative therapies in the treatment of chronic hepatitis C: a systematic review. J Hepatol, 2004; 40:491-500.

Da Silva CH, Sobrinho TJ, Castro VT, Lima DC, Amorim EL. Antioxidant capacity and phenolic content of CaesalpiniapyramidalisTul. and Sapiumglandulosum (L.) morong from northeastern Brazil. Molecules, 2011; 16:4728-39.

Guide for the Care and Use of Laboratory Animals. National Research Council (US) Committee for the update of the guide for the care and use of laboratory animals. 8th edition, National Academies Press (US), Washington, DC, 2011.

Ishihara K, Hirano T. IL-6 in autoimmune disease and chronic inflammatory proliferative disease. Cytokine Growth Factor Rev, 2002; $13: 357-68$
Lee SM, Michael UP. The protective effect of nitrendipine on gentamicin-induced renal failure in rats. Exp Mol Path, 1985; 43:107-14.

Li JY, Cao HY, Liu P, Cheng GH, Sun MY. Glycyrrhizic acid in the treatment of liver diseases: literature review. BioMed Res Int, 2014 $1-15$.

Manikanadan R, Beulaja M, Thiagarajan R, Priyadarsini A, Saravanan R, Arumugam M. Ameliorative effects of curcumin against renal injuries mediated by inducible nitric oxide synthase and nuclear factor kappa B during gentamicin-induced toxicity in wistar rats. Eur J Pharmacol, 2011; 670(2-3):578-85.

Mossanen JC, Tacke F. Acetaminophen-induced acute liver injury in mice. Lab Anim, 2015; 49:30-6.

Papackova Z, Heczkova M, Dankova H, Sticova E, Lodererova A, Bartonova L, et al. Silymarin prevents acetaminophen-induced hepatotoxicity in mice. PLoS One, 2018; 13(1):1-20.

Polini G, Romero R. Comer del monte. Plantas medicinales del Chaco Central. Cooperazione Internazionale Asunción, PA, 2013.

Poorrostami A; Farokhi F; Heidari R. Effect of hydroalcoholic extract of gingeron the liver of epileptic female rats treated with lamotrigine. Avicenna J Phytomed, 2014; 4:276-86.

Randjelović P, Veljković S, Stojiljković N, Sokolović D, Ilić I. Gentamicin nephrotoxicity in animals: current knowledge and future perspectives. EXCLI J, 2017; 16:388-99.

Reddy GJ, Reddy VP, Sreepavani M, Rajaramb C, Kumar SN, Kanhere RS. Evaluation of hepato protective potential of ethanolic extract of Ixorapavetta against isoniazid and rifampicin induced hepatotoxicity in rats. Drug invent today, 2013; 5:201-6.

Salih NA. Effect of nettle (Urticadioica) extract on gentamicin induced nephrotoxicityin male rabbits. Asian Pac J Trop Biomed, 2015; 5(9):756-60.

Tavafi M, Ahmadvand H. Effect of rosmarinic acid on inhibition of gentamicin induced nephrotoxicity in rats. Tissue Cell, 2011; 43(6):392-7.

Tulkens PM. Nephrotoxicity of aminoglycoside antibiotics. Toxicol Lett, 1989; 46:107-23.

Velmurugan V, Ganesan A. Hepatoprotective activity of methanol extract of stem bark of Prosopis cineraria Linn against carbon tetrachloride induced hepatotoxicity. Int J Pharm Pharm Sci, 2014; 6,491-3.

White CP, Hirsch G, Patel S, Adams F, Peltekian KM. Complementary and alternative medicine use bypatients chronically infected with hepatitis C virus. Can J Gastroenterol, 2007; 9:589-95.

How to cite this article:

Soverina MS, Campuzano-Bublitz MA, Centurión JR, Galeano AK, Kennedy ML. Preliminary evaluation of hepatoprotective and nephroprotective effects of Prosopis ruscifolia leaf extract in mice. J Appl Pharm Sci, 2019;9(12):037-041. 